\title{
Numerical Simulation of Stresses in Thin-rimmed Spur Gears with Keyway
}

B. Brůžek, E. Leidich

This paper contains an investigation of the key on a stress distribution in a thin-rimmed spur gear. A stress analysis was carried out by means of the Finite Element Method (FEM). The 2D-FE analysis has helped to find the influence of turning the gearing towards the keyway on the stress in the loaded root of the tooth and in the keyway. 2D and 3D numerical analysis has been used to find mutual influence of every single notch (root of tooth and keyway), influence of thickness of the hub, length of the key and the form of loading. Verification has been carried out through experimental method.

Keywords: gear, keyway, rim thickness.

\section{Introduction}

These days there is no generally accepted calculation for design of thin-rimmed asymmetric loaded hub with gearing which would take into account both - impact of the notch of root of the tooth and impact of the notch of the keyway. Therefore a designer prefers thicker wall of hub in the critical places, that means over dimensioning. Growing competition and increasing costs demand the measures which suppose to optimise constructional parts. However, there are still reserves in the hub with the keyway.

Thin-rimmed hub with gearing is used in many driving machine sets as a pinion in transmission, couplers and as a part of the braking mechanisms. Shaft-key-hub system is used very often, because of simple assembly and disassembly. During the testing of toothed wheels it was discovered that in the area of keyway crack initiation frequently occurs (Fig. 1). The cause are the notch stresses produced in the root of the tooth and in the keyway.

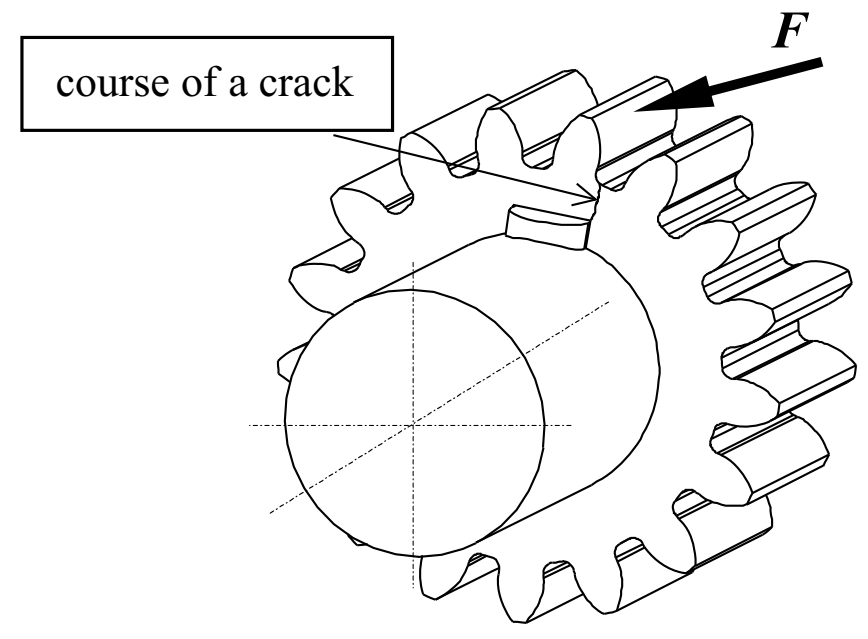

Fig. 1: Pinion with shaft and key

\section{Dimension assignation of the hub with gearing}

Geometrical dimensions of the shaft-key-hub system are standardized in DIN 6885 [2] and DIN 6892 [3]. Fig. 2 shows a valid designation according to these standards and fundamental geometrical dimensions for a description of the gearing as well. These are standardized according to DIN 3990 [1].

Important parameter for an analysis is minimum wall thickness $s_{k}$. It is defined as the shortest distance between the fillet of the keyway $r_{2}$ and the dedendum circle $d_{f}$ of the gearing, counted by equation [4]:

$$
s_{k}=\frac{d_{f}}{2}-\sqrt{\left(\frac{d_{w}}{2}+t_{2}\right)^{2}+\left(\frac{b}{2}\right)^{2}}+(\sqrt{2}-1) \cdot r_{2} .
$$

For a description of the loaded root of the tooth towards to the keyway of the hub was defined an angle $\varphi$. The angle $\varphi=0^{\circ}$ means, that the tooth $\mathrm{Z}_{4}$ lies symmetrical over the keyway of the hub.

For each of the investigations was used A Form of key (rounded ends). Either there were the key and the hub flushed or the load bearing length of the key corresponded to hub width. First case occurs often in the practice, the second is important to a comparison of the results of 2D-FE-analysis with experimental acquired results.

\section{Design of the FE-Model, boundary conditions}

Geometric dimensions used in numerical calculations are introduced in Table 1.

For absolute description of all aspects of investigated parameters should be designed a 3D-FE-Model of the shaft-key-hub system. For the reason that a evaluation of the 3D-Model is difficult and time demanding, most of the calculations were carried out with 2D-FE-Model (plane stress). There will be shown a sufficient agreement of the results of the 2D- and 3D-Models on the one geometrical variant. 

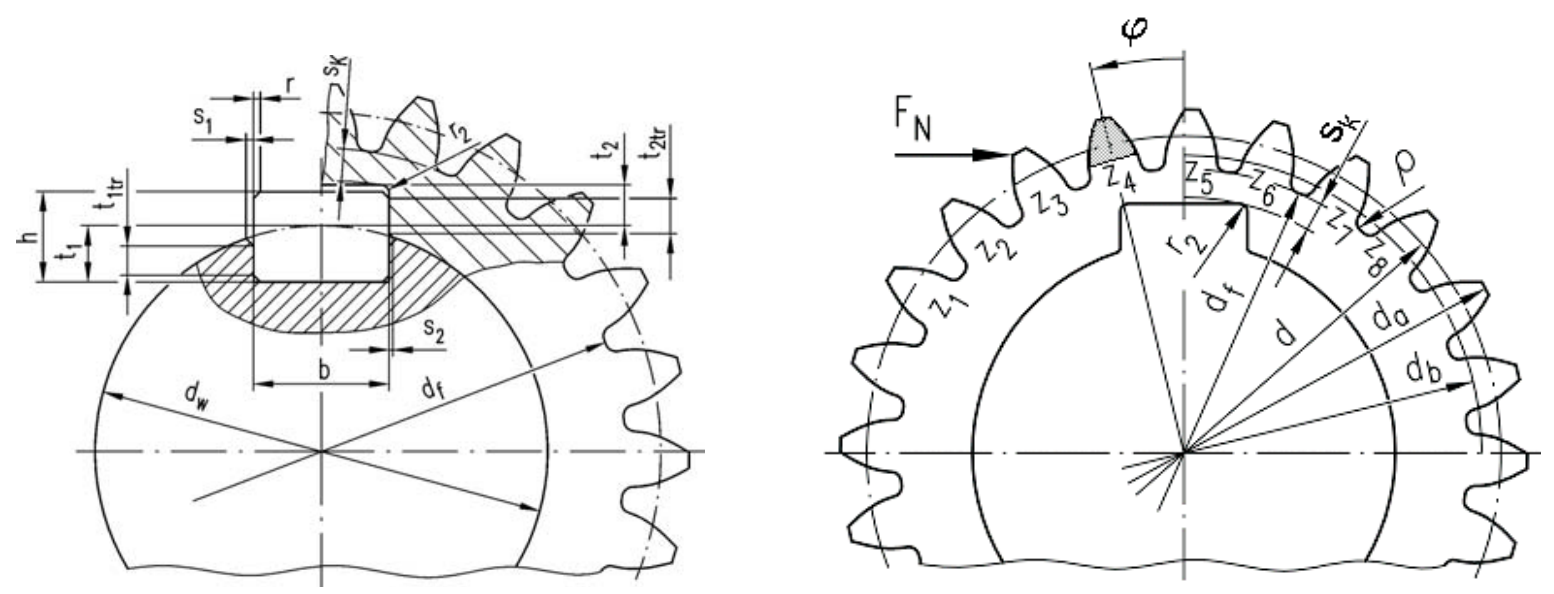

\begin{tabular}{|l|l|}
\hline$d_{w}$ & Diameter of the shaft \\
\hline$d_{f}$ & Dedendum circle \\
\hline$h$ & Height of the key \\
\hline$b$ & Width of the key \\
\hline$t_{1}$ & Depth of the keyway in shaft \\
\hline$t_{1 \mathrm{tr}}$ & Load bearing depth of the keyway in shaft \\
\hline$t_{2}$ & Depth of the keyway in hub \\
\hline$t_{2 \operatorname{tr}}$ & Load bearing depth of the keyway in hub \\
\hline$s_{1}$ & Chamfer or radius of the keyway in shaft \\
\hline$s_{2}$ & Chamfer or radius of the keyway in hub \\
\hline$r$ & Chamfer or radius of the key \\
\hline$r_{2}$ & Fillet of the keyway \\
\hline
\end{tabular}

\begin{tabular}{|l|l|}
\hline$d$ & Pitch circle \\
\hline$d_{f}$ & Dedendum circle \\
\hline$d_{a}$ & Addendum circle \\
\hline$d_{b}$ & Base circle \\
\hline$\rho$ & Radius of the root of the tooth \\
\hline$s_{k}$ & Minimum thickness of the hub \\
\hline$\varphi$ & Position from tooth $\mathrm{Z}_{4}$ to middle of the keyway \\
\hline
\end{tabular}

Fig. 2: Geometric dimensions of the shaft-key-hub system (left) and the fundamental geometrical dimensions of the gearing

Table 1: Geometric dimensions

\begin{tabular}{|c|c|c|c|c|}
\hline & \multicolumn{3}{|c|}{ Calculation variants } \\
\hline Module & $m$ & $2 \mathrm{~mm}$ & $2.5 \mathrm{~mm}$ & $4 \mathrm{~mm}$ \\
\hline Number of teeth & $z$ & 29 & 24 & 17 \\
\hline Diameter of the shaft & $d_{w}$ & \multicolumn{3}{|c|}{$40 \mathrm{~mm}$} \\
\hline Width of the hub & $b_{n}$ & \multicolumn{3}{|c|}{$40 \mathrm{~mm}$} \\
\hline Cross section of the key & & \multicolumn{3}{|c|}{ DIN $6885-\mathrm{A}-12 \times 8 \mathrm{~mm} \times \mathrm{mm}$} \\
\hline Fillet of the keyway & $r_{2}$ & \multicolumn{3}{|c|}{$0,25 \mathrm{~mm}$} \\
\hline Pitch circle & $d$ & $58.00 \mathrm{~mm}$ & $60.00 \mathrm{~mm}$ & $68.00 \mathrm{~mm}$ \\
\hline Minimum thickness of the hub (Eq. 1) & $s_{k}$ & $\approx 1.27 \times \mathrm{m}$ & $\approx 1.16 \times \mathrm{m}$ & $\approx 1.26 \times \mathrm{m}$ \\
\hline $\begin{array}{l}\text { Tooth root radius of the of the reference pro- } \\
\text { file }\end{array}$ & $\rho_{f P}$ & $0.75 \mathrm{~mm}$ & $0.94 \mathrm{~mm}$ & $1.50 \mathrm{~mm}$ \\
\hline
\end{tabular}

For an exact description of the investigated variant is necessary to model all components which are in mutual contact (shaft, key and hub). Because of a reduction of a computational time there were modeled only eight teeth along circumference in region of the keyway and three teeth lying opposite (as "non-attenuate" teeth, that means the teeth aren't influenced by the keyway). The other teeth have no influence on investigated problem. On the other hand it would be insufficient to model only a loaded tooth, since adjacent teeth influence stiffness of the researched zone. 


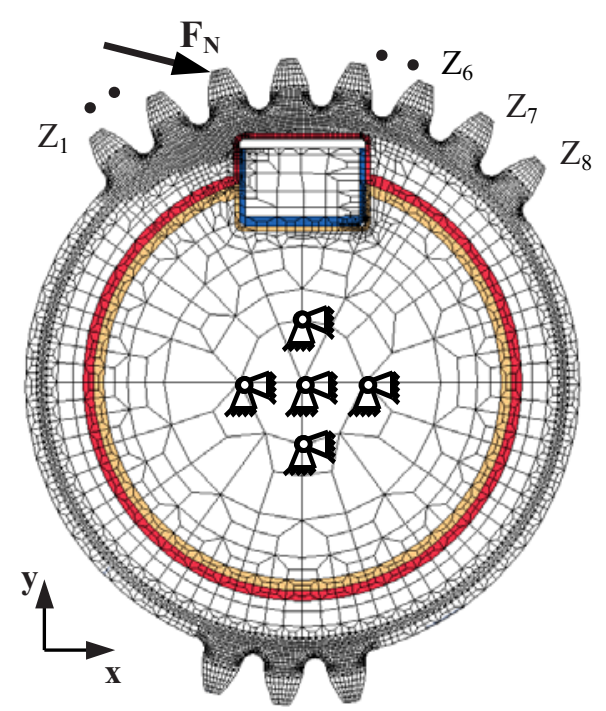

$$
u_{x}=u_{y}=\text { ofor shaft }
$$

- hub and key are over the contact condition statically determinate

Fig. 3: 2D-FE-Model of the shaft-key-hub system with boundary conditions; $F_{N}$ - normal force (example for tooth $\mathrm{Z}_{3}$ )

There is displayed 2D-Model and the boundary conditions in Fig. 3.

\section{2D-FE-Model}

At first the most loaded geometry was detected. The maximum stress was calculated in the root of the tooth and in the keyway for various geometrical variants. Next the eventuality of a recrimination of both opposite notches (root of tooth and keyway) was investigated.

Fig. 4 (left) shows the influence of the angle $\varphi$ on the maximum loading in the root of the tooth $\left(\sigma_{1 \max }\right)$ always for the loaded tooth and the module $2 \mathrm{~mm}$, that means the influence of the position of tooth $\mathrm{Z}_{4}$ on the symmetry plane (middle of the keyway). Resulting from the same calculations there is corresponding stress in the keyway displayed (Fig. 4 - right).

It is evident from the course of stress, as for the root of tooth that the maximum stress is at the angle $\varphi=2.5^{\circ}$ and by loading of the tooth $\mathrm{Z}_{3}$. By further turn and consecutive load- ing of the tooth $\mathrm{Z}_{4}$ the stress in the root of the tooth decreases again and goes even under basic stress [1]. The angle $\varphi$ has only a small influence upon the place of the maximum stress in the root of the tooth.

However, there is another situation by the loading of the keyway. During the sequential loading of the tooth with normal force rise two maximums of stress on different places in dependence on angle $\varphi$.

Fig. 4 also shows that there are always higher stresses in the root of the tooth. From whence it follows that the root of the tooth is ever a critical location and not the keyway. It is necessary to confirm this assumption by experiment.

It will focus mainly on the root of the tooth by further calculations.

It is possible to explain the stress distribution both in the root of the tooth and in the keyway from the deformation of a hub with eight teeth in the region of the keyway under rotary normal force loading. In Fig. 5 is a deformation displayed by

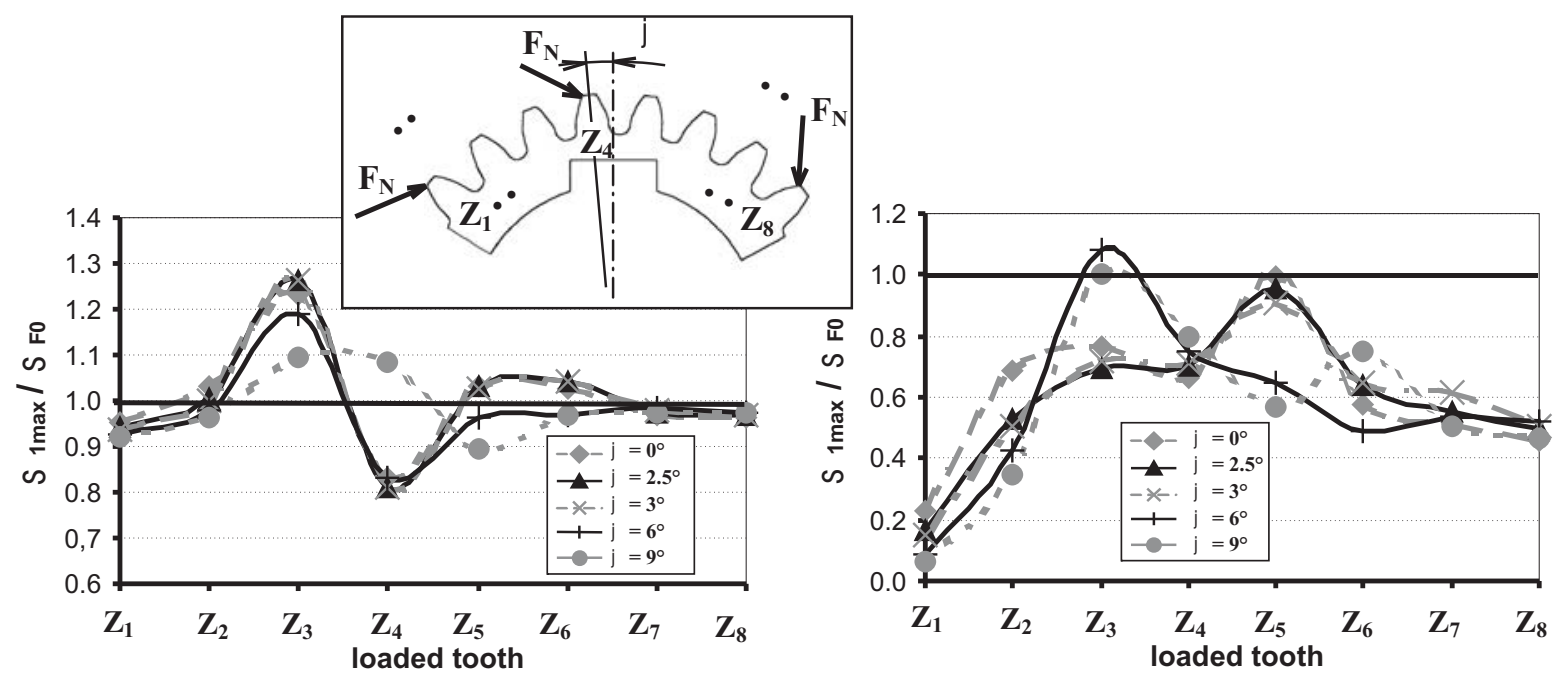

Fig. 4: Change of the maximum first principal stress in the loaded root of the tooth (left) and in the keyway (right) by rotating loaded tooth and various angles $\varphi$ for the hub with module $2 \mathrm{~mm}$; $\sigma_{\mathrm{F} 0}-$ characteristic value of stress 


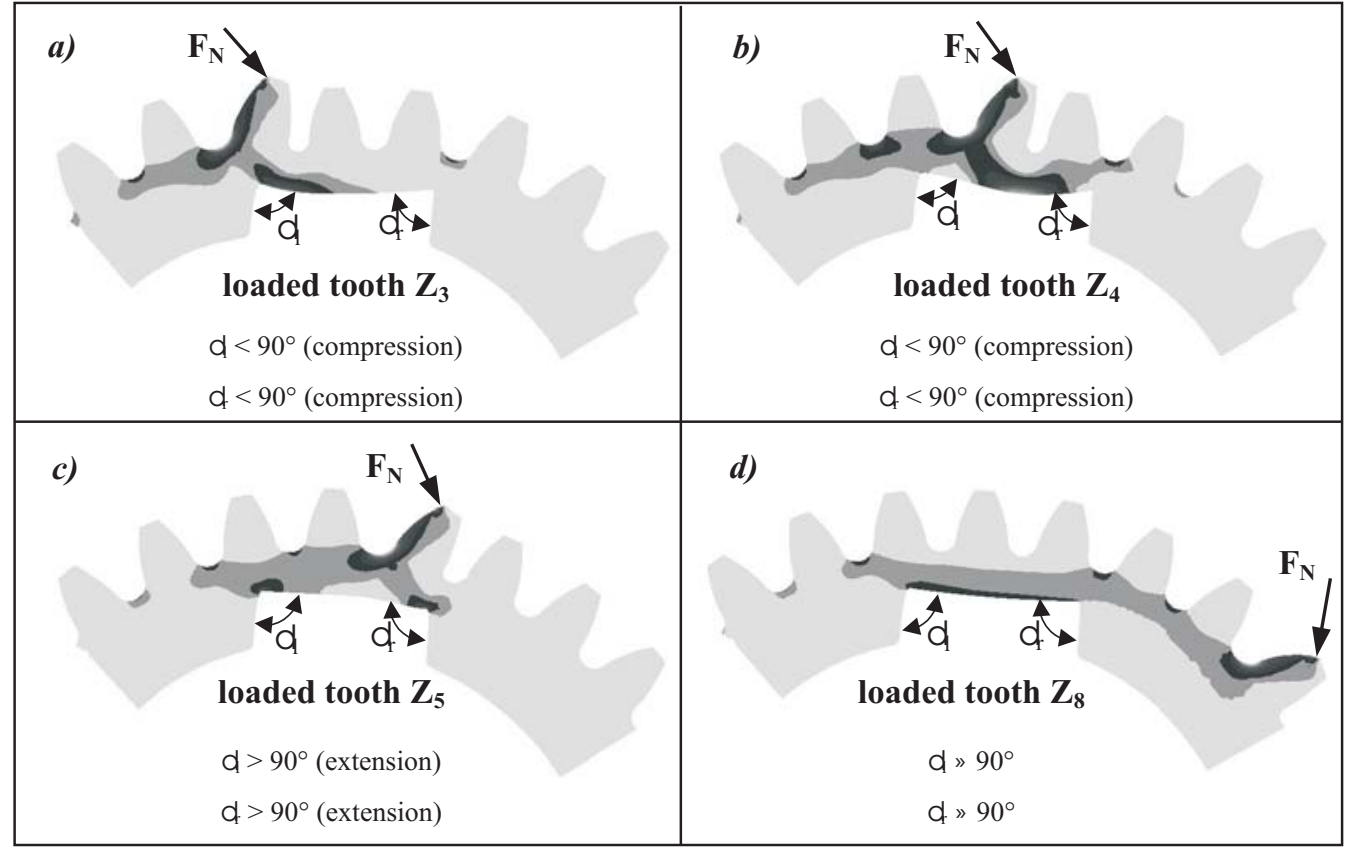

Fig. 5: Deformation of the hub with teeth in the region of the keyway

loading of the third, fourth, fifth and eighth tooth. It is obvious, that the maximum stress in the root of the tooth is always on the loaded tooth. However, there is quite different situation in the region of the keyway. The location of maximum stress varies. The angle between the bottom and the side of the keyway is smaller than $90^{\circ}$ by the loading of the teeth $\mathrm{Z}_{3}$ and $\mathrm{Z}_{4}$ and the maximum stress lies on the bottom of the keyway. By the loading of the tooth $\mathrm{Z}_{5}$ the angle between the bottom and the side of the keyway is bigger than $90^{\circ}$ and the maximum stress is in a fillet of the keyway. By the loading of the tooth $\mathrm{Z}_{8}$ the angle between the bottom and the side of the keyway is just about constant and there is no significant maximum stress in the region of the keyway.

\section{3D-FE-Model}

The 3D-calculations were carried out only for the critical case, that means for $\varphi=2,5^{\circ}$ by the loading of tooth $\mathrm{Z}_{3}$. To save a computational time the number of elements in un- loaded zones was more reduced in comparison with the 2D-Model. The basic boundary conditions for the 3D-Model are shown in Fig. 6. By the double-sided torque distribution both ends of the shaft are steadily supported. By the one-sided torque distribution the left end of the shaft is steadily supported and the right end of the shaft is supported only in a radial direction.

\section{Double-sided torque distribution}

Fig. 7 is determined to compare the $2 \mathrm{D}$ and $3 \mathrm{D}$ calculations. In the picture it is evident, that calculated stresses for 2D and 3D-Model are almost identical. Therefore it is possible to use 2D-Model for symmetric boundary conditions (double-sided torque distribution).

The first principal stress was evaluated in loaded area of the root of the tooth, that means between the tooth $\mathrm{Z}_{2}$ and the tooth $\mathrm{Z}_{3}$, and in the keyway. Fig. 8 shows evaluated areas and the stress distribution for double-sided torque distribution.
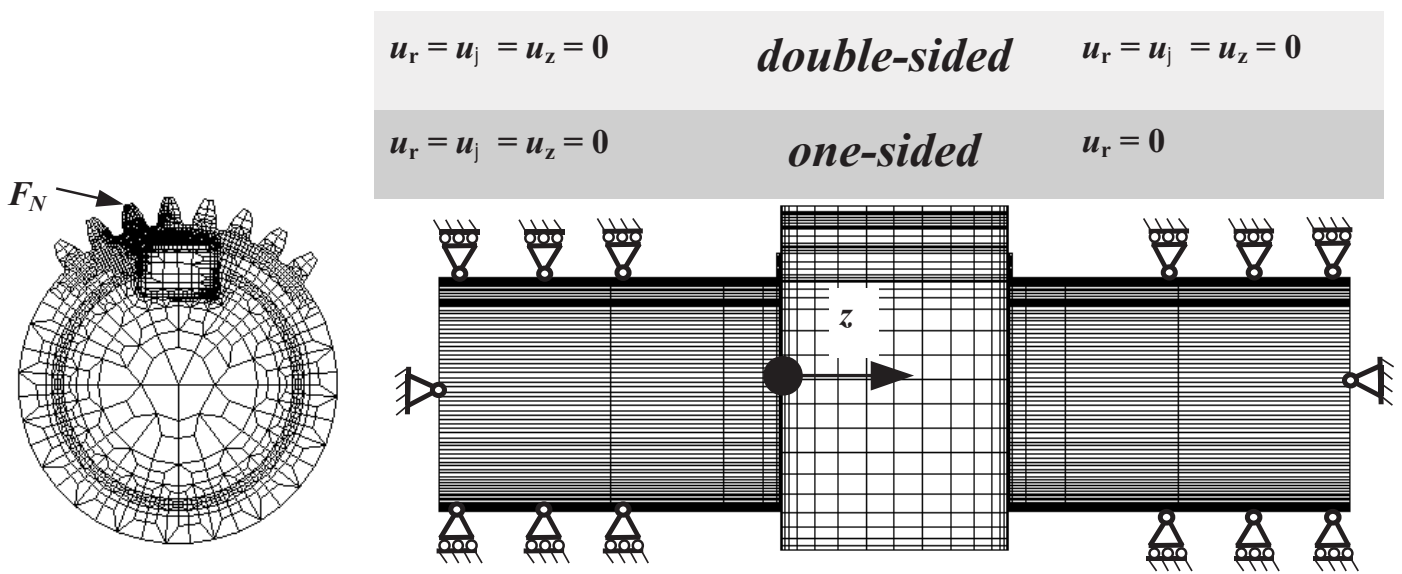

Fig. 6: Boundary conditions for 3D-Model, $\varphi=2.5^{\circ}$; Modul $2 \mathrm{~mm} ; F_{N}-$ normal force (tooth $\mathrm{Z}_{3}$ ) 

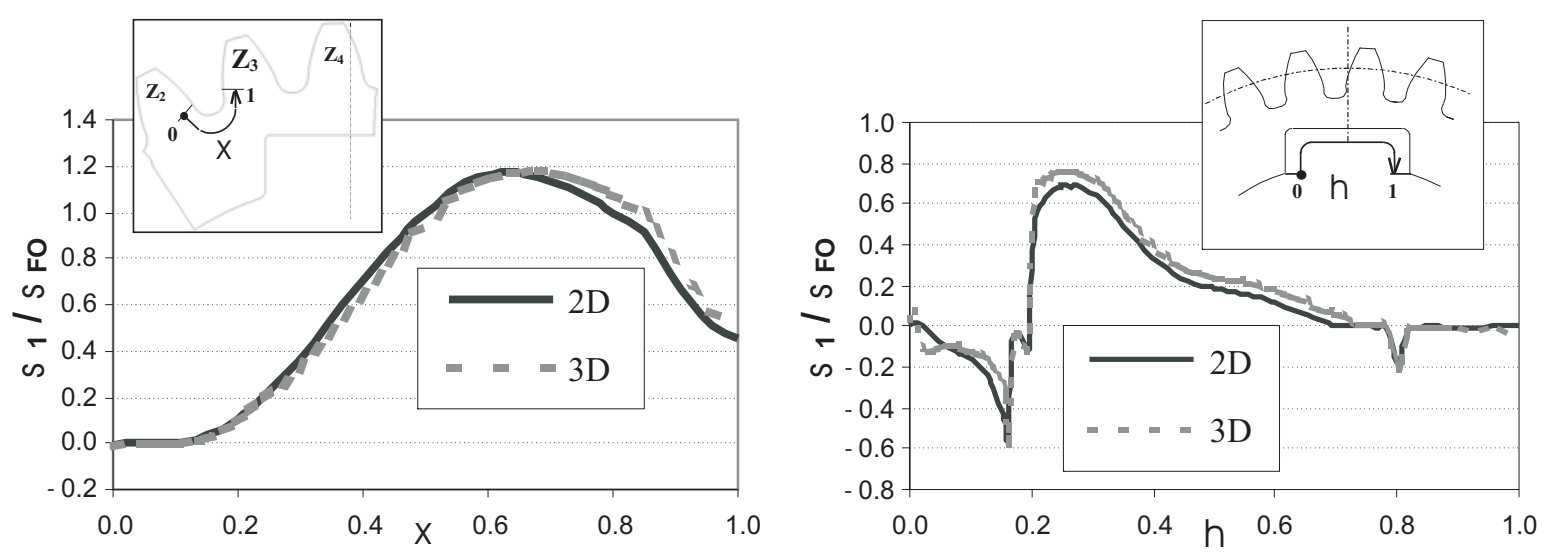

Fig. 7: Comparison of the results of the $2 \mathrm{D}$ and $3 \mathrm{D}-$ Model for module $2 \mathrm{~mm}, \varphi=2.5^{\circ}$ and load on tooth $\mathrm{Z}_{3}$. Left: stress distributions in loaded tooth radius; right: stress distribution in keyway; $\sigma_{\mathrm{F} 0}-$ characteristic value of stress.

\section{One-sided torque distribution}

In the Fig. 9 there is displayed an analog evaluation of the stress in the loaded root of the tooth and in the keyway for one-sided torque distribution. In the Fig. 9 is possible to identify only small influence of the asymmetrical loading. The result is, that the difference between double-sided and one-sided distribution of the torque is imponderable. This presumption is confirmed by experimental analysis.

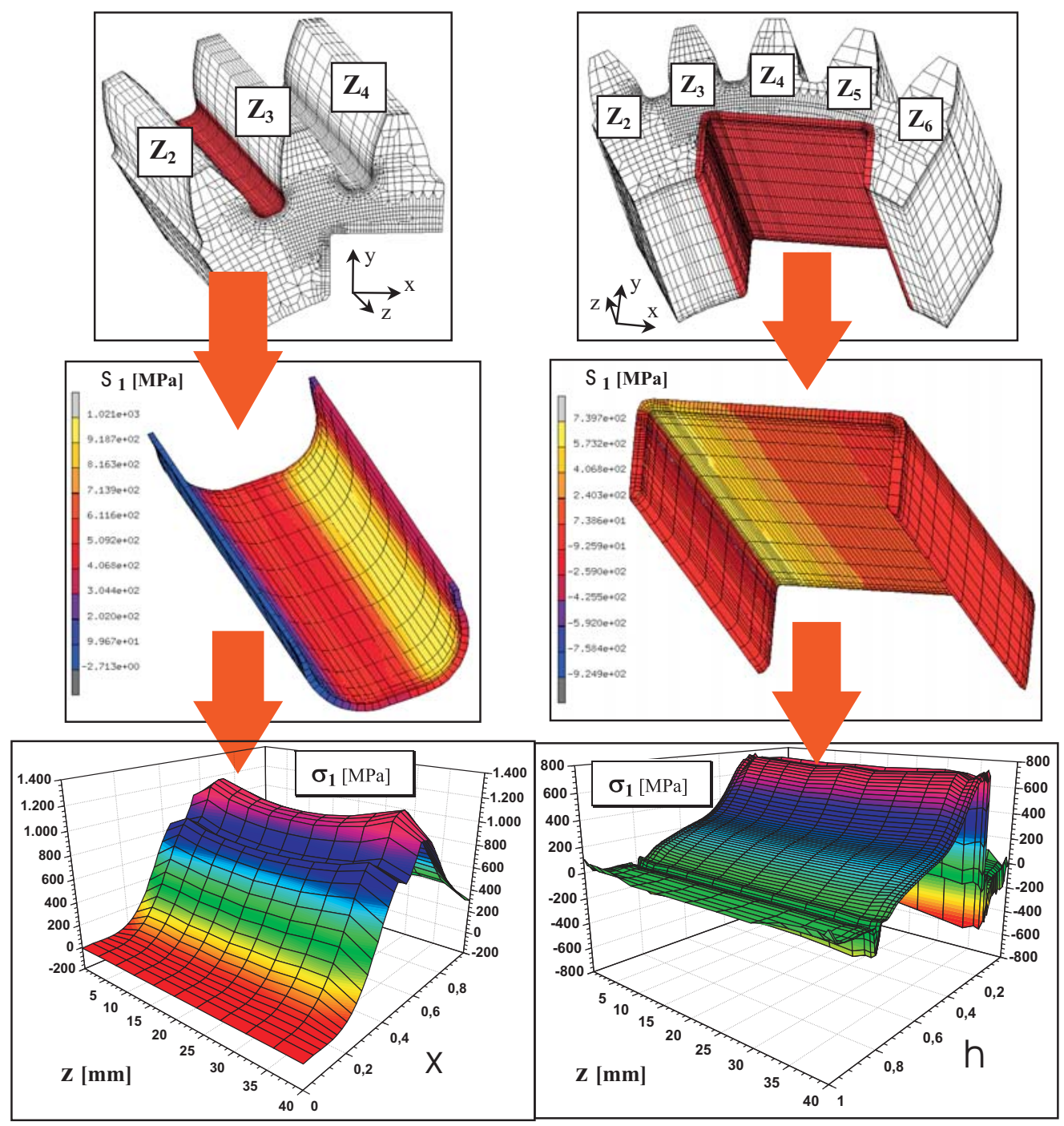

Fig. 8: Stress distribution in the loaded root of the tooth (left) and in the keyway (right) for double-sided torque distribution; $\varphi=2.5^{\circ}$; module $2 \mathrm{~mm}$; normal force on tooth $\mathrm{Z}_{3} ; \eta$, $\xi$ : see Fig. 7. 


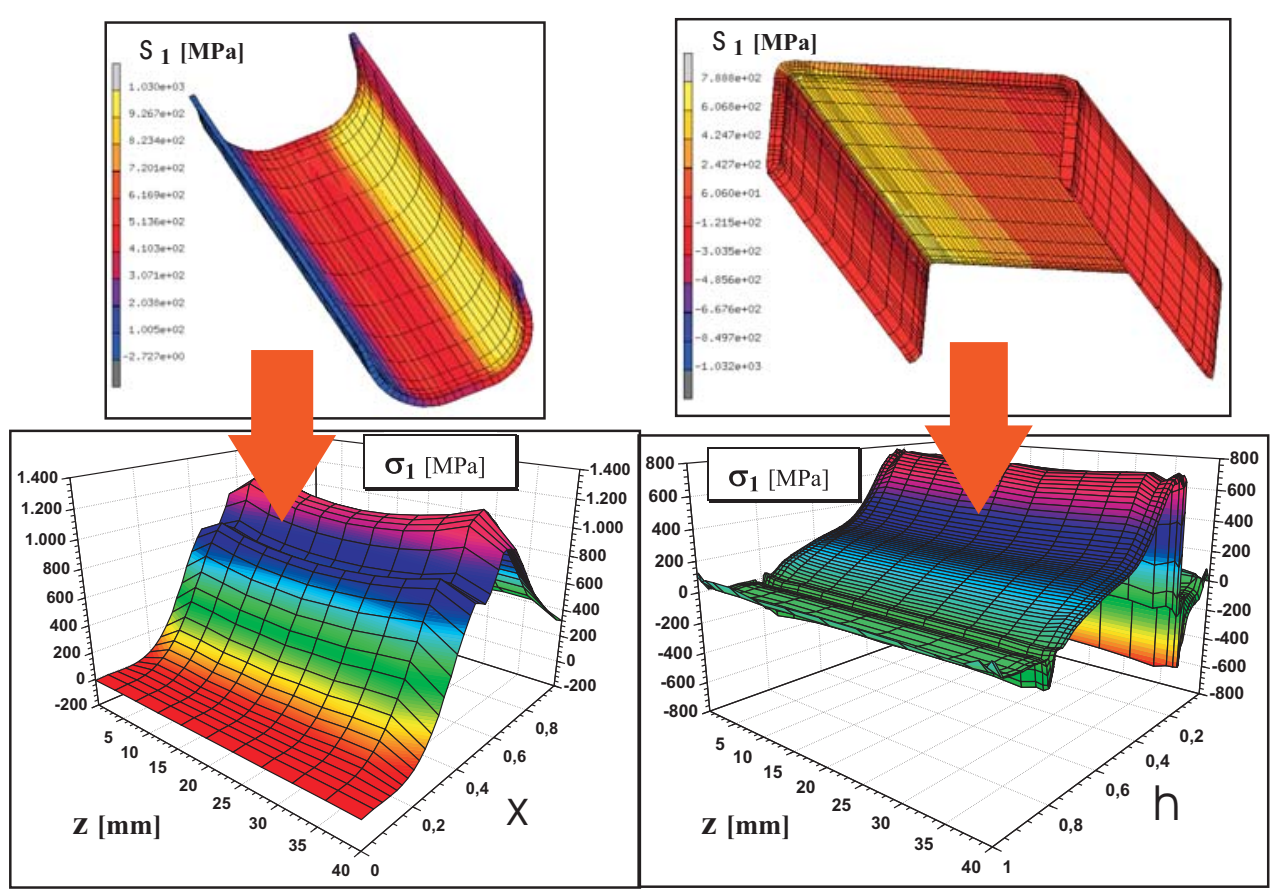

Fig. 9: Stress distribution in the loaded root of the tooth (left) and in the keyway (right) for one-sided torque distribution; $\varphi=2.5^{\circ} ;$ module $2 \mathrm{~mm}$; normal force on tooth $\mathrm{Z}_{3} ; \eta$, $\xi$ : see Fig. 7

\section{Length of the key}

In the practice the variant with the flush hub and key often occurs. Boundary conditions and force application are displayed in Fig. 6, the same as for an overhang key. The evaluation is analogue as well. The first principal stress was evaluated in the loaded root of the tooth and in the keyway. Stress distributions is shown in Fig. 10.

From the stress course in the keyway the influence of the length of the key is obvious. The stresses in the area of the keyway decrease on both ends of the hub, however they are bigger due to shorter supporting length of the key than by the overhang key. On the other hand stress distribution in the root of the tooth (Fig. $10-$ left) is similar to that one at the overhang key (Fig. 8 - left). Since the first principal stress is in the root of the tooth bigger than in the keyway, therefore the length of the key has no influence on a crack initiation for the hub with module $2 \mathrm{~mm}$. The crack initiation is always in the root of the tooth. This assumption was also successfully verified by the experimental method.

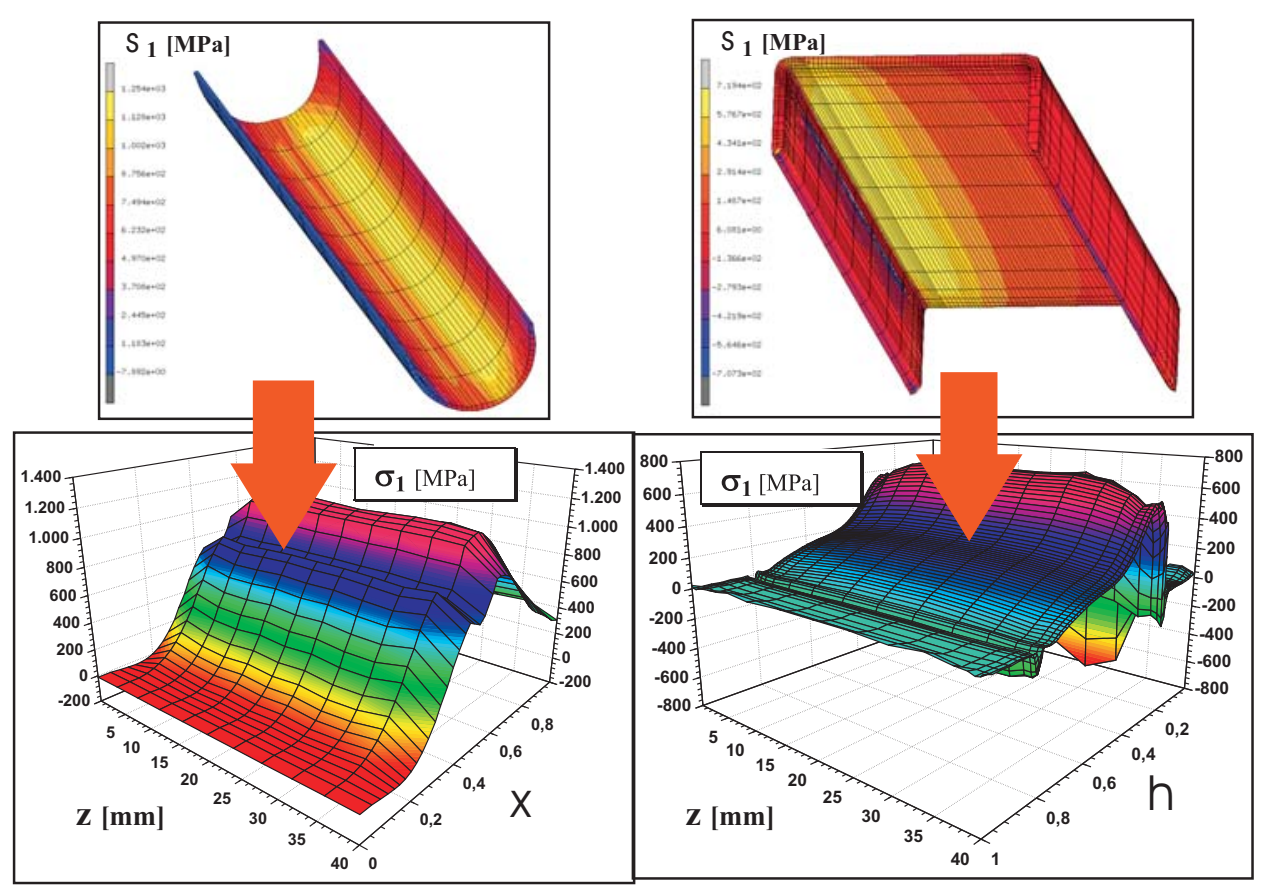

Fig. 10: Stress distribution in the loaded root of the tooth (left) and in the keyway (right) for double-sided torque distribution; $\varphi=2.5^{\circ}$; module $2 \mathrm{~mm}$; normal force on tooth $\mathrm{Z}_{3}$; hub and key flushed 


\section{Numerical investigated influences}

The influence of the keyway on stress increase in the root of the tooth is mainly due to small thickness of the hub $s_{k}$ (see Fig. 2). The stress distribution was evaluated in the root of the tooth and in the keyway for various thicknesses of the hub $s_{k}$ always for the critical geometry of the hub with module $2 \mathrm{~mm}$. Fig. 11 shows exemplary maximum values of the first principal stress in the root of the tooth and in the keyway depending on dimensionless thickness of the hub. From the picture it is evident that from definite hub thickness the keyway has no influence on the stress in gearing.

For assessment of strength behaviour of thin rimmed spur gears with keyway is important to consider interaction both notches (root of the tooth and fillet of the keyway) which lie close together. From the calculations in [5] results that for various fillets of the keyway the stress distribution in the root of the tooth stays identical. As well as for various radiuses of the tooth root the stress distribution in the keyway stays similar. That means that by the used minimum thickness of the hub (see Table 1) both notches do not influence each other.

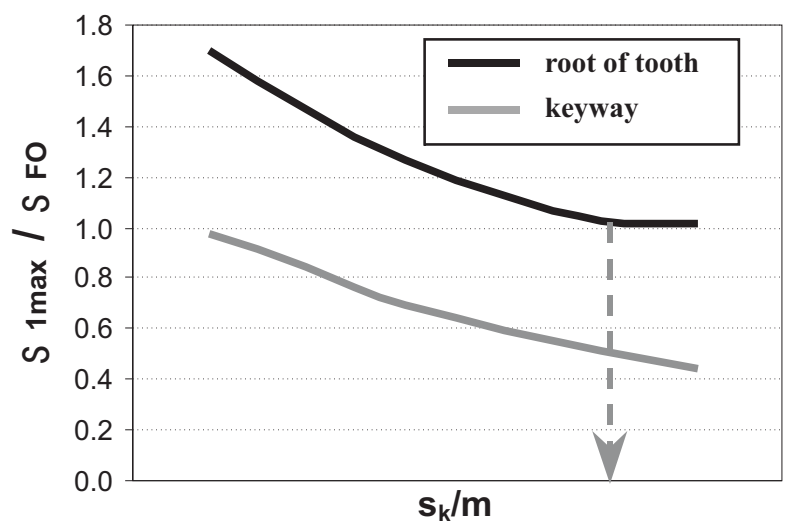

Fig. 11: Maximum first principal stress in the loaded root of the tooth and in the keyway depending on dimensionless thickness of the hub with module $2 \mathrm{~mm}$; $\sigma_{\mathrm{F} 0}$ - characteristic value of stress

Beyond calculations for the hub with module $2 \mathrm{~mm}$ was also counted with modules $2.5 \mathrm{~mm}$ and $4 \mathrm{~mm}$. For each module the influence of the angle $\varphi$ on the maximum loading in the root of the tooth and in the keyway was investigated.

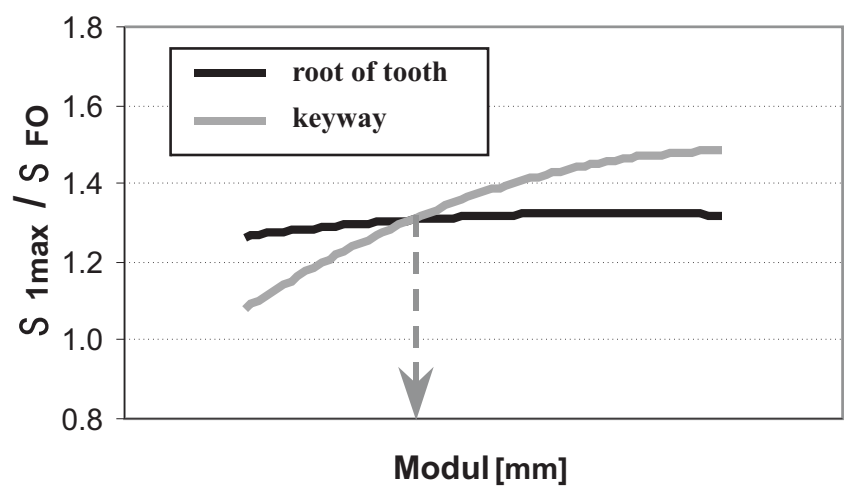

Fig. 12: Maximum first principal stress in the loaded root of the tooth and in the keyway depending on module always for the critical position of the keyway; $\sigma_{\mathrm{F} 0}-$ characteristic value of stress
Fig. 12 represents maximum values of the first principal stress depending on module, always for critical angle $\varphi$ in the loaded root of the tooth and in the keyway for the constant minimum thickness of the hub $s_{\mathrm{k}}$. From the picture is evident that until definite module the maximum first principal stress in the root of the tooth is bigger than in the keyway, while for the greater module the maximum loaded place moves towards the keyway. Depending on the stress gradient in both notches the initiation of the crack moves accordingly, also from the root of the tooth towards the keyway.

\section{Conclusion}

In this paper the stress distribution in the thin-rimmed spur gears with the keyway is investigated. The results show that not only the hub thickness between the root of the tooth and the keyway has the big influence on the stress increase but also the position of the gearing towards the keyway. On the other hand the form of the loading (one-sided and double-sided torque distribution) and the length of the key (hub and key flushed and overhang key) have only small influence. From the calculations it is also evident that for small module the maximum first principal stress is bigger in the root of the tooth than in the keyway while for the greater module the maximum loaded place moves towards the keyway. Verification of the numerical calculations has been carried out through the experimental method.

\section{References}

[1] DIN 3990, Tragfähigkeitsberechnung von Stirnrädern. Beuth Verlag, 1987.

[2] DIN 6885, Mitnehmerverbindungen ohne Anzug; Passfedern, Nuten, Hohe Form; Abmessungen und Anwendung. Beuth Verlag, 1968.

[3] DIN 6892, Mitnehmerverbindungen ohne Anzug - Passfedern Berechnung und Gestaltung. Beuth, 1998.

[4] Floer, M.: Beanspruchungsanalyse an torsionsbelasteten Passfedernabe. Aachen: Shaker, 2000.

[5] Leidich, E., Brůžek, B.: Verzahnte dünnwandige Naben mit Passfederverbindung. AiF - Abschlussbericht, 2002.

Dipl. Ing. Bohumil Brůžek

phone: +493715314572

fax: +493715314560

e-mail: bohumil.bruzek@mb.tu-chemnitz.de

Prof. Dr. Ing. Erhard Leidich

phone: +493715314660

fax: +493715314560

e-mail: erhard.leidich@mb.tu-chemnitz.de

Department of Engineering Design

Chemnitz University of Technology

Reichenhainer Straße 70

09126 Chemnitz, Germany 